\title{
O MÉTODO DO CASO NA EDUCAÇÃO JURÍDICA
}

\author{
Horácio \\ Wanderlei \\ Rodrigues ${ }^{1}$ \\ Marcus Vinícius Motter \\ Borges $^{2}$
}

\begin{abstract}
Resumo
O objeto de estudo do artigo é o Método do Caso. E seu objetivo consiste em analisar a aplicação dessa ferramenta no âmbito da Educação Jurídica. Para tanto, são analisadas as principais abordagens teóricas do processo de ensino-aprendizagem, destacando aquelas que são centradas no aluno; também são identificados os papéis do estudante e do professor em cada uma delas. Logo após, enquadrando o Método do Caso como estratégia focada no aluno, serão traçadas delimitações e diferenciações entre o Método do Caso e o Estudo de Casos, de forma a justificar a utilização neste texto da expressão Método do Caso. Posteriormente, verifica-se como o Método do Caso corrobora os objetivos do processo de ensino-aprendizagem no tocante à compreensão de conteúdos e desenvolvimento de habilidades, competências e comportamentos. $\mathrm{Na}$ sequência o trabalho analisa os tipos de casos que podem ser utilizados, os cuidados necessários para sua escolha e formulação, bem como apresenta um conjunto de elementos a serem considerados quando da elaboração de casos. Finalmente, apresenta as etapas a serem seguidas pelo professor para a sua adequada utilização como estratégia didática.
\end{abstract}

Palavras-chave: Método do Caso. Estudo de Casos. Casos para ensino. Educação Jurídica. Ensino do Direito. Ensino Jurídico.

\section{INTRODUÇÃO}

\footnotetext{
${ }^{1}$ Doutor em Direito (Filosofia do Direito e da Política) pela Universidade Federal de Santa Catarina (UFSC). Mestre em Direito (Instituições Jurídico-Políticas) pela UFSC. Professor Titular de Teoria do Processo do Departamento de Direito (DIR) e Professor Permanente do Programa de Pós-Graduação em Direito (PPGD) da UFSC. Sócio fundador do Conselho Nacional de Pesquisa e Pós-Graduação em Direito (CONPEDI) e da Associação Brasileira de Ensino do Direito (ABEDi). Membro do Instituto Iberomericano de Derecho Procesal (IIDP). Pesquisador do Conselho Nacional de Desenvolvimento Científico e Tecnológico (CNPq). Coordenador do Núcleo de Estudos Conhecer Direito (NECODI). E-mail: horaciowr@gmail.com

${ }^{2}$ Doutorando em Direito no Programa de Pós-Graduação em Direito (PPGD) da Universidade Federal de Santa Catarina (UFSC). Professor Assistente do Departamento de Direito da UFSC. Professor de diversos cursos de Pós-Graduação em Santa Catarina, entre eles UNIVALI, UNISUL, CESUSC, Católica, UNIDAVI e UNC. Professor da Escola Superior da Advocacia (ESA/OAB/SC) e da Escola do Ministério Público de Santa Catarina. Vice-presidente da Comissão de Estudos do novo Código de Processo Civil da OAB/SC. E-mail: marcus_borges@hotmail.com
} vol.09, nº. 03, Rio de Janeiro, 2016. pp. 
A realidade complexa e mutante do mundo contemporâneo exige, em todos os campos, constante evolução. Na educação, em especial na Educação Jurídica, o cenário não poderia ser diferente e, assim, o processo de ensino-aprendizagem nos Cursos de Direito deve estar em recorrente evolução e aprimoramento.

As diversas abordagens teóricas que objetivam explicar o processo de ensinoaprendizagem preocupam-se com o objeto, com o sujeito e com a interação entre sujeito e objeto do conhecimento; possuem, cada uma delas, um enfoque predominante em um ou em outro desses elementos. Contudo, nos últimos anos, as abordagens que propõem a adoção de estratégias ativas de ensino, focadas no aluno, tem recebido maior destaque.

Nesse cenário surge a utilização do Método do Caso como interessante alternativa de estratégia de ensino-aprendizagem nos Cursos de Direito. Assim sendo, o objetivo do presente artigo consiste em analisar a aplicação dessa ferramenta, identificando eventuais problemas e tecendo possíveis soluções. Para tanto, incialmente analisar-se-á as principais abordagens teóricas do processo de ensino-aprendizagem, com destaque para aquelas que são centradas no aluno, bem como serão identificados os papeis de estudantes e de professores em cada uma delas. Logo após, enquadrando o Método do Caso como estratégia focada no aluno, serão traçadas delimitações e diferenciações entre ele e o Estudo de Casos, de forma a justificar a utilização neste texto da expressão Método do Caso.

Posteriormente, verificar-se-á como o Método do Caso corrobora os objetivos do processo de ensino-aprendizagem no tocante à compreensão de conteúdos e desenvolvimento de habilidades, competências e comportamentos. Na sequência o trabalho analisará os tipos de casos que podem ser utilizados, os cuidados necessários para sua escolha e formulação, bem como apresentará um roteiro para a elaboração de casos. Por fim, apresentará as etapas a serem seguidas pelo professor para a sua adequada utilização como estratégia didática.

Com isso se espera contribuir para a discussão acadêmica acerca das ferramentas que podem ser utilizadas no processo de ensino-aprendizagem no âmbito da Educação Jurídica, em especial àquelas que denotam a adoção de estratégias focadas no aluno.

\section{ESTRATÉGIAS ATIVAS NO PROCESSO DE ENSINO-APRENDIZAGEM}

A complexidade do processo de ensino-aprendizagem exige a utilização das mais variadas estratégias didáticas, objetivando uma maior facilidade do aluno na compreensão dos conteúdos e o desenvolvimento de competências e habilidades. Para tanto é necessário que professor tenha 
conhecimento das diversas estratégias e abordagens, bem como tenha capacidade de escolher as ferramentas mais pertinentes no contexto da disciplina e do projeto pedagógico do curso em que está inserido.

Nessa linha existem diversas abordagens que objetivam explicar e detalhar o processo de ensino-aprendizagem. Em interessante ensaio, Roberto Vatan dos Santos (2005) faz uma análise comparativa entre algumas delas, tomando como critério quatro aspectos relevantes: a escola, o aluno, o professor e o processo de ensino-aprendizagem. Assim, o autor compara as abordagens tradicional, comportamentalista, humanista, cognitivista e sociocultural sob a égide desses critérios. Para fins do presente ensaio, importa tecer breves comentários sobre as três últimas abordagens, pois o método a ser analisado guarda relação com elas.

$\mathrm{Na}$ abordagem humanista o foco reside no sujeito do processo, ou seja, o ensino é centrado no aluno, que é um ser ativo, criativo e participativo e que tende a aprender a aprender. O professor é, portanto, um facilitador e estimulador da aprendizagem. A escola deve ser democrática, oferecendo condições para o desenvolvimento da autonomia do aluno e permitindo, no processo de ensino-aprendizagem, que conteúdos programáticos possam ser selecionados conforme os interesses dos discentes.

$\mathrm{Na}$ abordagem cognitivista, igualmente, o foco é o aluno, o qual desempenha um papel ativo para comparar, experimentar, levantar hipóteses, analisar e argumentar diante dos conteúdos e situações que são a ele apresentadas. Para tanto, o professor tem o papel de criar situações inovadoras e desafiadoras que despertem no discente essa atitude ativa. A escola deve oferecer ao aluno liberdade de ações e criar um ambiente desafiador e favorável a motivação. $O$ processo de ensino-aprendizagem reconhece e valoriza o fato do sujeito estar inserido em um determinado contexto social e, por isso, o aprendizado se opera por meio de trocas contínuas com o meio em que ele está inserido.

A abordagem sociocultural, originada do trabalho de Paulo Freire na alfabetização de adultos, da mesma forma tem seu foco principal no aluno, o qual, além de ser ativo, deve possuir a consciência de operar mudanças na realidade social, ou seja, deve desempenhar um papel transformador. Nessa perspectiva o professor coloca-se, juntamente com o aluno, como sujeito do conhecimento, além de mediador do processo de ensino-aprendizagem. A escola deve proporcionar ao aluno múltiplas formas de aprender, sempre se preocupando com o contexto no qual está inserido. Já o processo de ensino-aprendizagem busca o desenvolvimento de uma consciência crítica no aluno, sendo que os temas geradores para o ensino devem ser extraídos da vida prática e de situações reais vivenciadas pelos discentes. 
As estratégias didáticas são ferramentas (RODRIGUES, 2012, p. 32) sempre vinculadas - em maior ou menor grau - a uma ou algumas abordagens pedagógicas. E devem ser dominadas pelos professores e adequadamente utilizadas no processo de ensino-aprendizagem. Por isso é papel do docente ter conhecimento do maior número possível dessas ferramentas, saber manuseá-las e, principalmente, escolher de forma adequada a melhor ferramenta para determinada situação, considerando a abordagem pedagógica à qual está vinculada.

Tais estratégias podem ser reunidas em algumas categorias, tendo como critério a relação existente entre os sujeitos e os elementos que formam o processo de ensino-aprendizagem, ou seja, entre professores, alunos e conteúdo. Assim, as estratégias podem ser divididas em: centradas no professor; interativas; e centradas no aluno. (RODRIGUES, 2012, p. 1). Para a concretização dos objetivos deste artigo é importante focar no último desses conjuntos, porquanto Método do Caso se encaixa em tal categoria.

As estratégias centradas no aluno propõem que "a busca do conhecimento ocorra de forma individual, partindo de textos, casos, problemas ou outros pontos de partida propostos pelos professores". (RODRIGUES, 2012, p. 11). Consistem em interessantes ferramentas a serem conjugadas de forma complementar às demais, de modo a proporcionar uma melhor compreensão dos conteúdos e o exitoso desenvolvimento de competências e habilidades pelo aluno.

Nesse sentido, o Método do Caso pode ser uma ferramenta didática indicada para os processos de ensino-aprendizagem propostos pelas abordagens cognitivista, humanista e sociocultural. Ou seja, percebe-se que o Método do Caso é ferramenta constante nas abordagens centradas no aluno, mas também pode ser utilizada no âmbito das abordagens interacionistas.

Formulado esse enquadramento é necessário, neste ponto, focar no papel do aluno e do professor nessas abordagens e nessa estratégia didática específica.

Como já dito, o aluno deve ter participação ativa. "A figura passiva de um aluno receptor do conhecimento transmitido pelo professor não mais se adapta à̀ efervescência cultural e política da época contemporânea, em especial pela grande quantidade de informações recebidas no cotidiano, por formas as mais variadas." (CARLINI, 2006. p. 88). Demonstrar interesse e curiosidade para a compreensão do conteúdo. Sua postura deve ser de experimentar, pesquisar, argumentar, comparar, formular hipóteses e testá-las, interagir com o mundo real e tentar transformá-lo, e de aprender a aprender.

Todavia, para que o estudante tenha essa postura, esse desempenho proativo, se faz necessário que o professor não exerça um papel que impeça tal conduta; ao contrário, seu 12621200 vol.09, nº. 03, Rio de Janeiro, 2016. pp. 1366 
comportamento deve incentivá-la. Nessa linha, tem-se que a função do professor é de facilitador, problematizando o conteúdo e indicando o meios e locais mais adequados de pesquisa e obtenção de conhecimento, bem como alertando para os inadequados. "O professor facilitador eì aquele que cria condições para que os alunos aprendam. Por isso, participa ele próprio de forma intensa desse processo, propondo problemas, questões, indagações e outras provocações que os instiguem permanentemente a buscar conhecimento para soluciona-las." (CARLINI, 2006, p. 88). Alguns autores preferem a expressão mediador, mais ligada às abordagens interacionistas; a expressão facilitador está mais ligada às abordagens centradas no aluno.

O professor também exerce papel de estimulador, ao apresentar ao aluno situações desequilibradoras e desafiadoras, as quais despertem seu interesse e o façam se sentir estimulado na busca de soluções. Da mesma forma, o professor deve agir como um contextualizador, apresentando ao aluno questões concretas e condizentes com a sua realidade, de modo a proporcionar nele uma consciência crítica de transformação.

Para Paulo Ghuiraldelli Júnior (2000, p. 35), na defesa de uma teoria educacional pósmoderna, é necessário como primeiro passo a "apresentação direta de problemas e situações problemáticas, ou mesmo curiosas e difíceis - questões culturais, éticas, étnicas, de convivência entre gêneros, mentalidades e modelos políticos diferentes". Nesse sentido, o papel do professor facilitador, estimulador e contextualizador, quase que desenvolvendo um papel de tutor, é fundamental para o alcance dos objetivos das estratégias focadas no aluno.

\section{MÉTODO DO CASO E ESTUDO DE CASOS}

Devido a sua utilização nos mais variados campos da ciência, o trabalho com casos acaba adotando diferentes formatos e nomenclaturas conforme a área de conhecimento. Da mesma forma, o Método do Caso e o Estudo de Casos, podem, além de serem confundidos um com o outro, serem também confundidos com outras metodologias ativas existentes, mas que com ele não se confundem.

O Estudo de Casos é empregado, no campo das Ciências Sociais, como instrumento de pesquisa científica; Maria Arlinda de Assis Menezes (2009, p. 133) afirma de forma categórica: “O estudo de caso eì uma estratégia de pesquisa”. Nessa perspectiva, sua aplicação requerer um procedimento próprio com planejamento, estabelecimento de premissas, desenvolvimento de um protocolo, pesquisas de campo, entrevistas e outros. 
O denominado Método do Caso não possui o mesmo objetivo do Estudo de Casos na concepção anteriormente descrita. É ele, segundo Antônio Carlos Gil (2004, p. 8), uma estratégia de ensino através da qual "uma parte da realidade eì trazida para a sala de aula para ser trabalhada pelos alunos e pelo professor.” Para Esdras Borges Costa (2007, p. 29):

Além de problematizar, o método do caso serve para se aprender, eì essencialmente didático. Aprender, desde logo, a colocar-se (o aluno), com imaginação, no lugar social de um decisor real em uma situação real.

Assumir o lugar de outrem eì uma prática indispensável em qualquer situação social, para variados fins. No caso didático, essa prática tem o fim específico de se aprender dentro do contexto de um curso (ou disciplina) participativo.

Trata-se, portanto, nessa segunda perspectiva, de uma estratégia do processo de ensinoaprendizagem na qual o estudante se depara com um caso - real, hipotético ou uma articulação de ambos - para analisá-lo e, a partir daí, chegar a uma série de conclusões objetivando a compreensão do conteúdo e o desenvolvimento de determinadas competências e habilidades. "[...] com o método do caso, o aluno passa a ser, vicariamente, um personagem da narração; como tal, ele passa pela identificação do problema, das alternativas de decisão, da escolha de uma delas, e da construção de sua implementação. As soluções alternativas (e a selecionada) não se limitam aÌs previstas ou recomendadas nas aulas teoìricas." (COSTA, 2007, p. 26).

Percebe-se, assim, a nítida diferença entre o Estudo de Casos, como instrumento de pesquisa científica, e o Método do Caso, como estratégia do processo de ensino-aprendizagem. Nessa linha:

Conforme o explicitado, evidencia-se o método do estudo de caso como uma estratégia para se conduzir uma pesquisa empírica, exigindo uma preparação prévia por parte do pesquisador e a organização de um planejamento da pesquisa. $O$ método do caso, ferramenta pedagógica inventada em fins do século XIX, se constitui em uma maneira de conduzir a educação de advogados, juristas e administradores de empresa, nada tendo, portanto, de similar com o método de estudo de caso. (MENEZES, 2009, p. 134).

Pensando especificamente na Área do Direito, o Método do Caso é assim descrito por Ramos e Schorscher:

O Método de Caso, na tradição norte-americana, é um instrumento didático que objetiva o ensino de habilidades voltadas para o desenvolvimento e a prática do raciocínio jurídico por meio da análise de decisões judiciais. Essa ferramenta didática enfatiza mais a 
fundamentação e os argumentos que embasam a solução proposta do que a resolução do caso em si, embora tenha sofrido alterações em sua conceituação ao longo da história. (2009, p. 49).

Particularmente, com relação à definição do Método do Caso considerada mais adequada ao ensino do direito nos países cujo sistema jurídico seja a civil law, é necessário que o aluno aprenda a compreender e a utilizar o vocabulário e a argumentação típicos dos tribunais (judiciais e administrativos). [...] O Método do Caso, no contexto dos países cuja fonte de direito é a lei, tem uma definição distinta da norte-americana. Ela não se restringe à mera extração de princípios e normas jurídicas de decisões judiciais, tampouco abrange toda formulação estratégica pretendida nas escolas de administração e economia. (2009, p. 58)

Para Ramos e Schorscher (2009, p. 58), ante as variações que esse método sofreu ao longo das últimas décadas, pode-se afirmar que existem vários Métodos do Caso. Assim, na versão do Método do Caso em que "a reflexão jurídica não se esgota no raciocínio dogmático, sendo também relevante o raciocínio estratégico", ele se aproxima muito do Problem Based Learning (PBL), causando algumas dificuldades de compreensão e diferenciação entre eles.

O PBL, ou Aprendizagem Baseado em Problemas (ABP) em português, é uma metodologia ativa muito utilizada nos Cursos de Medicina. Resumidamente pode-se dizer que ela se caracteriza pela utilização de sete passos, a saber: (1) leitura do problema e esclarecimento dos termos difíceis; (2) definição dos problemas a serem entendidos e explicados; (3) análise dos problemas, com as explicações necessárias; (4) elaboração de resumos; (5) formulação dos objetivos do aprendizado; (6) estudo individual baseado no passo 5; (7) apresentação dos relatórios ao grupo; discussão. (SEBASTIANY, BASTOS; 2011). A ABP não será, entretanto, objeto de estudo neste artigo. Da mesma forma não será objeto deste artigo o Estudo de Casos; o objeto aqui abordado será especificamente o Método do Caso, como estratégia de ensinoaprendizagem.

\section{MÉTODO DO CASO E PROCESSO DE ENSINO-APRENDIZAGEM}

O processo de ensino-aprendizagem possui alguns objetivos, entre eles podem ser destacados a compreensão dos conteúdos e o desenvolvimento de competências, habilidades e comportamentos. A utilização do Método do Caso, de forma adequada, pode lograr êxito na tarefa de alcançar esses objetivos. 
Com relação à compreensão do conteúdo parece claro que as teorias, as classificações, os institutos básicos, os conceitos e as categorias podem sim ser compreendidos pelo aluno por meio de casos. Em determinadas situações, é claro, será necessária uma introdução teórica ou conceitual sobre a matéria, a qual poderá ser fornecida ao aluno com aulas expositivas ou material para leitura individual. Igualmente, pode ser imprescindível o esclarecimento de alguns termos técnicos ainda desconhecidos. Contudo, nada disso impede que a utilização do Método do Caso alcance o objetivo de fazer o aluno compreender o conteúdo.

O Método do Caso possibilita ao aluno - diante de um problema que lhe é apresentado o desenvolvimento de competências e habilidades. As competências e habilidades dizem respeito à utilização dos conteúdos, quer no plano mais abstrato do raciocínio, quer no plano mais prático da execução. É comum utilizar a expressão competência para a primeira situação e a expressão habilidade para a segunda. Não há, entretanto, na literatura especializada uma unanimidade sobre essa classificação, sendo que é comum utilizar as expressões como sinônimas. (RODRIGUES, 2014a, p. 259).

Competência trabalhadas pelo Método do Caso são, dentre outras: interpretar a situação; identificar, diagnosticar e delimitar o problema posto; separar, dentro do problema, aquelas questões ou informações que são mais relevantes; e tecer e sistematizar possíveis soluções para o problema. Já no plano das habilidades - mais prático, de execução - o Método do Caso permite que o aluno: redija, aplique e teste as soluções levantadas para o problema; verifique quais as consequências da aplicação destas soluções, bem como preveja eventuais soluções alternativas; e improvise e modifique seu plano inicial diante do surgimento de situações inesperadas.

$\mathrm{Na}$ educação superior o desenvolvimento e avaliação de comportamentos possui menos espaço quando comparado com o educação infantil e fundamental mas, ainda assim, pode ser encontrado, por exemplo, nos estágios (RODRIGUES, 2014a, p. 259). Contudo, os casos são um campo fértil para a questão dos comportamentos. Isso porque tais atividades podem ser realizadas em grupos de alunos e, assim, é possível analisar o comportamento do aluno ao trabalhar em equipe, identificando perfis: aqueles que se colocam de forma mais ativa, ou mais reativa; os que possuem perfil de lideres, para guiar o grupos ao estabelecimento e aplicação de soluções; os que tem mais facilidade para organizar e exteriorizar suas ideias; entre outros.

Da mesma forma, o Método do Caso pode incluir debates entre os grupos, de modo que os alunos sejam desafiados a expor suas ideias e soluções para o caso apresentado, bem como que tentem convencer os demais, ou alguém que esteja fora do debate (até mesmo o próprio 
professor), da pertinência e adequação das soluções propostas. Nesse contexto, certamente, serão identificados alunos que possuam perfil de argumentar, explanar e convencer os demais.

\section{BONS CASOS E OBJETIVOS DE APRENDIZAGEM}

O Método do Caso é muito utilizada em cursos das áreas de Saúde, de Administração e de Economia, dentre outros. No Direito sua utilização é verificada mais comumente nas disciplinas com aplicação mais prática, nada obstando, contudo, a aplicação em disciplinas de cunho teórico.

O ponto de partida para a utilização do Método do Caso é, justamente, a escolha do caso, o qual pode ser real, simulado, ou até mesmo um caso real com algumas adaptações. Deve ser um caso curioso, contextualizado com a realidade do aluno, daquela instituição de ensino e com o cenário socioeconômico no qual ele está inserido, possibilitando discussão e reflexão, bem como comportando uma solução ideal e possíveis soluções alternativas. $\mathrm{O}$ caso necessita primar por aproximar o aluno do mundo real, da realidade prática do Direito, de modo que se possa conjugar de forma prática as teorias e conhecimentos já obtidos. Em resumo, o caso deve ser simples, objetivo, motivador e capaz de despertar no aluno interesse e vontade de buscar soluções (RODRIGUES, 2010, p. 42).

Segundo Andrew Grahan (2010, p. 38) bons casos são os que fomentam o trabalho e o debate em grupo, independentemente do seu tamanho e da forma como agrupa as informações. Para ele um bom caso, para ser utilizado no processo de ensino aprendizagem, deve ser:

1. Aberto: não limitado a apenas uma resposta certa.

2. Conectado a conhecimentos previamente adquiridos ou relevantes, cruciais para os objetivos pedagógicos.

3. Evocativo: questões que provoquem diferentes opiniões, perspectivas e debates.

4. Relevante para a cultura, a conjuntura atual e os objetivos de aprendizagem em pauta.

5. Sustentável: independentemente de sua extensão, fornecer informações, complexidades e desafios suficientes para que seja proveitoso durante todo o tempo do exercício. (2010. p. 44).

Sylvia Maria Azevedo Roesch (2007, p. 216), ao dissertar sobre a elaboração de casos em

Cursos de Administração de Empresas, afirma que bons casos:

i) contêm uma ou mais questões gerenciais a serem confrontadas e selecionadas, por meio de debate; (ii) tratam de tópicos relevantes para a área; (iii) proporcionam uma viagem de descoberta que permite separar sintomas de problemas mais fundamentais; (iv) levantam controvérsias que proporcionam diferentes interpretações, decisões e planos de ação; (v) contêm contrastes e comparações; (vi) permitem aos participantes generalizar lições e conceitos subjacentes no caso para outras situações; (vii) contêm dados apropriados, nem vol.09, nº. 03, Rio de Janeiro, 2016. pp. 
demais, nem de menos, para tratar dos problemas como descrição do produto, indústria e mercado, pessoas envolvidas e dados quantitativos; (viii) têm um toque pessoal porque incluem a fala dos participantes e a descrição de processos organizacionais formais e informais; (ix) são bem estruturados e bem relatados; (x) são curtos, no máximo 8 a 10 páginas de texto e ateì 5 páginas de anexos.

Justamente por isso, o caso precisa ser escolhido considerando uma série de questões. Duas merecem aqui um destaque especial: (a) o estágio do curso em que o aluno se encontra; e (b) quais objetivos de aprendizagem que se busca atingir com aquele caso.

Quanto ao primeiro ponto, parece claro que não é possível exigir de um aluno em início de curso um raciocínio complexo que envolva questões muitos específicas ou sistemáticas do ordenamento jurídico com o um todo. Em tais alunos, por via de regra, inexiste uma maturidade em termos de conhecimento jurídico que lhes proporcione os subsídios necessários para a elaboração de soluções adequadas para casos mais complexos. Da mesma forma, deve-se atentar que os casos tendem a ser interdisciplinares, exigindo conhecimentos, ainda que gerais ou superficiais, de outras matérias além daquela em que o caso está sendo aplicado. Por isso, se faz cogente observar quais são esses conhecimentos inerentes a outras disciplinas e verificar se o alunos já os compreendeu.

A questão dos objetivos de aprendizagem a serem alcançados com aquele caso específico denota um pouco mais de atenção. Isso porque o tipo de caso a ser formulado depende diretamente daquilo que se pretende como objetivo didático do processo de ensinoaprendizagem.

Os casos, portanto, serão formulados de acordo com os objetivos de aprendizagem. É claro que a escolha de um ou outro tipo de caso dependerá de inúmeros outros fatores. Dentre eles já foi destacado inicialmente o estágio do curso que o aluno se encontra, o que envolve também o seu nível de maturidade e conhecimento sistêmico do ordenamento jurídico. Por isso, o professor deve estar atento ao escolher ou formular um caso, para que não ocorra um resultado negativo no alcance dos objetivos pedagógicos.

Insta salientar, ainda, que - dependendo do tipo de caso - será imprescindível a disponibilização de material de apoio ao aluno, além do próprio caso. Assim sendo, pode ser interessante, por exemplo, repassar ao aluno a íntegra dos autos da ação judicial em que o caso é debatido - se essa for a situação -, documentos, contratos, pareceres, análises técnicas, notícias de jornais, julgados dos tribunais superiores sobre o tema e outros materiais que possam auxilialo. Tudo isso contribui para que o estudante tenha uma melhor percepção do caso, bem como esteja mais inteirado com a situação fática e, por isso, o mais próximo possível de uma situação 
real. Dessa forma será mais fácil despertar no discente um espírito ativo, participativo e crítico, comportamento esse que se coaduna com as estratégias ativas.

\section{ESPÉCIES DE CASOS DE ENSINO}

Existem diversas classificações sobre os tipos de casos, dependendo, em especial, dos critérios adotado e dos objetivos almejados. Uma classificação bastante conhecida é a formulada por Antônio Carlos Gil (2004, p. 11) para os casos utilizados nos Cursos de Administração:

1. Caso-ilustraçąo. Constitui a modalidade mais simples. Restringe-se aÌ apresentação de uma situação verificada no contexto de uma determinada organização. De modo geral, nestes casos não se solicita do estudante a sua análise com vistas aİ tomada de uma decisão, pois esta jaì eì apresentada na descrição. Esta modalidade de caso eì utilizada para ilustrar situações de forma individual ou comparativa [...].

2. Caso-anaìlise. Propõe aos estudantes a análise do caso, mediante sua decomposição em partes significativas e a identificação da relação entre as variáveis. São muito utilizados em sala de aula com o objetivo de desenvolver a capacidade analítica. Sua elaboração não demanda cuidados muito maiores do que os requeridos para o caso-ilustraçaPo. Sua aplicação, no entanto, exige maior dedicação do estudante, bem como preparação do professor.

3. Caso-problema. Constitui o tipo mais complexo e tem como objetivo desenvolver nos estudantes muito mais do que a capacidade analítica. Ele requer do estudante a elaboração de uma síntese com base nos dados apresentados e apresentação da melhor solução possível para o problema. Os casos-problema com mais elevado nível de estruturação são os que seguem o modelo da Universidade de Harvard. Estes casos costumam requerer do estudante mais do que a solução do problema, pois nem sempre este aparece claramente no texto. Os estudantes têm que identificaì-los, apresentar possíveis soluções e ponderar as vantagens e desvantagens de cada uma delas.

Partindo dessa classificação, adota-se neste texto uma divisão ainda mais simplificada, com apenas dois grupos de casos:

1. Casos demonstração: são os casos elaborados para serem utilizados em aulas expositivas tradicionais, para ilustrar o conteúdo ministrado; o caso-análise e o caso-ilustração da classificação de Antônio Carlos Gil enquadram-se nessa categoria; 
2. Casos problema: são os casos elaborados para serem utilizados no âmbito do Método do Caso; ou seja, são problemas elaborados para utilização em uma metodologia ativa, centrada no aluno e não no professor; não servem para ilustrar uma exposição, mas para provocar a busca do conhecimento pelo próprio aluno.

Há diversas outras classificações, com uma maior diversidade nas espécies de casos apresentados. Especificamente para este artigo, a classificação apresentada (e sua versão simplificada) atende aos objetivos pedagógicos propostos: diferenciar os casos problema, a serem utilizados no Método do Caso, dos casos demonstração, utilizados na aulas expositivas.

Relativamente aos casos problema é possivel ainda oferecer diferentes possibilidades, dependendo do objetivo pedagógico buscado. Essas diferentes possibilidades são muitas vezes apresentadas sob outras denominações na literatura especializada. Considerando a opção de adotar uma divisão simplificada, entre casos para aulas expositivas (casos demonstração) e casos para o Método do Caso (casos problema), propositalmente essas diferentes possibilidades estão aqui englobadas sob uma mesma denominação - casos problema - visto não haver sentido, neste texto, em adotar-se outras classificações que não trariam nenhum ganho em termos dos objetivos inicialmente propostos.

Primeiramente é possível trabalhar com um caso que já contenha no texto a sua solução (ou possíveis soluções) e os resultados obtidos a sua aplicação. Nele é inserida a situação fática ocorrida, o problema que foi gerado, a solução que foi pensada e aplicada e, ao final, os resultados alcançados com a aplicação da dita solução; tem-se uma situação já finalizada (como acontece quando se trabalha com a análise de autos findos) e decisões judiciais já transitadas em julgado. A situação fática gerou o problema que foi enfrentado com uma solução, a qual produziu determinados resultados ou consequências (também indicados no texto). Nesse tipo de caso se espera do aluno uma análise da situação como um todo, a identificação dos pontos positivos e negativos da solução que foi implementada e, principalmente, a proposição de soluções alternativas as quais, potencialmente, poderiam gerar melhores resultados ou consequência mais positivas. Pode também indicar novos problemas oriundos da decisão tomada e implementada, gerando, por consequência, novos casos problema para análise.

A segunda alternativa é trabalhar com um caso buscando identificar os problemas e também apresentar suas soluções. Nessa opção, o aluno se depara com um caso em que tão somente lhe é apresentada uma situação ocorrida. Com isso, ele deverá identificar os potencias problemas que podem surgir, analisar e propor eventuais soluções para cada um dos problemas, bem como prever os resultados possíveis de cada uma destas soluções. 
A terceira possibilidade, que se assemelha muito com a segunda, consiste em apresentar a situação ocorrida e os problemas já identificados. Nessa opção, o caso se resume em narrar ao aluno a situação fática ocorrida e o problema que foi gerado. Diante desse cenário ele irá propor soluções viáveis de resolução do problema, experimentando-as e, por conseguinte, identificando os resultados possíveis de cada uma dessas soluções. O fato de não ser apresentada nenhuma solução no caso, certamente, abrirá um espaço criativo maior para que o aluno formule sua própria solução sem estar influenciado por outras já estabelecidas.

Também é possivel uma alternativa na qual seja oferecido o caso, o problema e a solução, mas sem indicar os resultados ou consequências decorrentes da decisão tomada; ou seja, são apresentados a situação fática, o problema e a solução que foi planejada para enfrentar o problema sem, contudo, serem apresentados os resultados obtidos. Essa é uma alternativa intermediária entre a primeira e as duas outras opções apresentadas. $\mathrm{O}$ aluno deverá analisar a solução proposta, com suas vantagens e desvantagens, e identificar os possíveis resultados que serão obtidos com ela, tanto os positivos quanto os negativos. Com isso, poderá verificar que a solução proposta, por exemplo, não é a melhor e, assim, sugerir outras soluções. Pode também indicar novos problemas oriundos da decisão tomada e implementada, gerando, por consequência, novos casos problema para análise.

A próxima seção será dedicada de forma mais direta aos cuidados e orientações quando da elaboração de casos, mais especificamente de casos problema. Nela serão trabalhadas as etapas da elaboração, a estrutura do texto e os cuidados que devem ser tomados relativamente à forma de narrar os casos.

\section{ELABORANDO CASOS PARA ENSINO}

Esta seção do artigo foi elaborada tendo como base a produção sobre o tema existente para a Área de Administração. De um lado, praticamente não há literatura sobre o Método do Caso na Área do Direito, com exceção dos materiais mais recentes produzidos no âmbito dos projetos da GV Direito; de outro lado, a Área da Administração pertence às Ciências Sociais Aplicadas, mesmo âmbito no qual se encontra a Área do Direito. Nesse contexto, parece ser essa a opção mais adequada.

Sylvia Maria Azevedo Roesch (2007, p. 215), em artigo denominado Notas sobre a construção de casos para ensino, destaca que um caso-problema não se resume à descrição de uma determinada situação ou de um problema (ou conjunto de problemas); ele deve conter uma 
história. Ou seja, redigir um caso para ensino é diferente de redigir um trabalho acadêmico (como um artigo, por exemplo). Considerando essa situação a autora coloca três desafios a serem enfrentados quando da elaboração de casos para ensino:

Em primeiro lugar, o desafio do redator de casos para ensino é selecionar aspectos de uma situação problemática e estruturar o seu texto para contemplar certos objetivos educacionais, sem no entanto revelar no corpo do caso quais são estes objetivos. Os objetivos educacionais são declarados nas notas de ensino dirigidas ao professor.

Em segundo lugar, a construção de casos para ensino requer desaprender o relato argumentativo próprio da redação científica. Assemelha-se ao jornalismo factual, sendo o texto recheado de fatos e depoimentos, apresentados em ordem cronológica, com o objetivo de proporcionar uma discussão bem informada do caso em sala de aula. Mas não há, no texto, um narrador defendendo uma ideia ou opinião ou analisando a prática com base em teoria, como no texto acadêmico. Tampouco há espaço para a retórica e a ideologia, pois o propósito não é persuadir o leitor, mas possibilitar o aparecimento de diversas interpretações que emerge da discussão do caso.

Em terceiro lugar, o texto deve ser capaz de atrair o leitor e animar a discussão do caso: no caso ideal, o relato é vívido, revela conflitos e até contém um pouco de mistério. Por esta razão, incluem-se nele algumas características de outros gêneros de textos, ao exibir, por exemplo, incidentes ou diálogos que realçam ou apontam os problemas do caso. Em certos momentos, vale-se de narrativa sutil, mais ao estilo de um conto, em que o sub texto é dado pelo objetivo educacional subjacente ao relato.

Também Roesch (2011), em outro artigo, denominado Como narrar um caso para ensino, destaca que a elaboração de um bom caso pressupõe pesquisa de campo. Considerando as especificidades de área, talvez esse pressuposto colocado para a Área de Administração possa ser minimizado no que se refere à espécie de pesquisa; entretanto, no geral o pressuposto se mantém: para redigir um bom caso é necessário pesquisar; na Área do Direito essa pesquisa envolve, em especial, pesquisa bibliográfica e documental; jornais, revistas, sites, autos de processos, julgados dos tribunais e outras fontes podem contribuir decisivamente na qualidade dos casos elaborados.

Segundo Everton Rodrigues da Silva e Yan Marinho (2012, p. 6-10), em artigo intitulado Caso de ensino: o que é e como ele pode auxiliar o ensino da Administração no Brasil, a elaboração de casos de ensino envolve seis estágios, a saber: 


\section{Identificação do problema}

É a definição do escopo do caso, a identificação da questão central que norteará a redação do caso e que deve ser solucionada pelos alunos. Para que se possa elaborar um caso a ser trabalhado em situações em ensino aprendizagem, primeiro é preciso definir claramente o seu propósito em termos de conteúdo a ser trabalhado; o problema surge então como elemento aglutinador.

\section{Definição dos objetivos}

Todo caso de ensino deve possuir objetivos pedagógicos a serem atingidos pelos alunos: conteúdos a serem apreendidos, competências e habilidades a serem trabalhadas. O caso tem de ser elaborado de forma a levar os alunos a buscarem os conteúdos e a trabalharem as competências e habilidades pensados pelo autor quando da sua redação.

\section{Pesquisa e coleta de informações}

A redação de um caso pressupões pesquisa, como já destacado anteriormente. Livros, revistas, sites, trabalhos acadêmicos - monografias, dissertações, teses -, julgados de tribunais, documentos legislativos, enfim textos e documentos que tratem do objeto enfocado pelo caso. Esse levantamento serve tanto para o elaborador do caso, na sua redação, quanto para reunir material a ser indicado aos professores que vierem a utiliza-lo em suas salas de aula.

\section{Análise da dificuldade do caso}

A classificação dos casos com base em seu grau de dificuldade é um ponto importante para que se possa definir em que níveis e turmas de ensino ele pode ser utilizado. Ou seja, devese considerar o nível de dificuldade que o estudante terá na sua resolução. Elaborar casos para turmas iniciais é diferente de elaborar casos para turmas em final de curso. Da mesma forma é diferente elaborar casos para cursos de graduação e para cursos de pós-graduação; e dentro desses últimos, elaborar casos para alunos de especialização, mestrado e doutorado.

\section{Construção do caso}

É a redação do caso em si. Esse ponto específico merece um tratamento mais detido, que será feito na sequência, nesta mesma seção do presente artigo. 


\section{Teste do caso}

Por teste do caso entende-se a sua submissão à apreciação de pessoas que possuam conhecimento sobre o tema. Esse teste é importante para analisar se ele é capaz de atingir os objetivos de ensino a que se propõe; também permite conferir se o grau de dificuldade é realmente o desejado quando de sua redação. Após a aplicação do teste, dependendo dos resultados obtidos, pode ser necessário realizar ajustes na narrativa do caso; em casos extremos, de avaliação totalmente negativa, pode ser mais prudente descartar o texto e reiniciar o trabalho, retornando ao primeiro estágio e refazendo integralmente o caso de ensino.

Antônio Carlos Gil (2004, p. 5-10), em artigo intitulado Elaboração de casos para o ensino de Administração, indica uma número maior de etapas: (1) identificação do problema; (2) definição dos objetivos; (3) localização do caso; (4) coleta da informação requerida; (5) análise da dificuldade do caso; (6) preparação da primeira versão do caso; (7) teste do caso; e (8) redação do caso.

$\mathrm{Na}$ realidade o esquema de seis estágios exposto anteriormente, segundo seus próprios autores, tem por base esse esquema de oito etapas proposto por Gil. A primeira diferença está em que Gil inclui a localização do caso como uma etapa; mas essa etapa só tem sentido se for ser utilizado um caso já existente (em sua redação original ou como base para a elaboração de um novo caso). A segunda está na inclusão de duas etapas de redação, uma destinada à primeira versão e outra destinada à versão final, realizada após o teste do caso.

Quanto à construção do caso em si - sua estrutura -, adaptando para a área de Direito a proposta de Roesch (2011, p. 2), é possível dizer que o texto que o narra deve conter:

\section{Resumo}

O resumo, que em termos de tamanho pode ser feito nos moldes indicados pela ABNT, deve conter o indicativo de quem é o protagonista, a situação na qual está envolvido, o espaçotempo em que os fatos ocorreram, bem como especificar o dilema do protagonista. Também deve indicar as matérias ou disciplinas nas quais o caso pode ser trabalhado.

\section{Introdução}

Deve identificar o protagonista e situar o leitor no espaço-tempo em que se desenvolve o caso. Como no resumo, deve também informar a situação fática na qual está envolvido o 
protagonista e qual o seu dilema. Segundo Roesch $(2011$, p. 3) deve estar contida em um parágrafo e pode ser apresentada "na forma de um incidente, uma fala ou outro artifício narrativo que provoque no leitor o desejo de ler o texto por inteiro".

\section{Situação fática e contexto espaço-tempo}

As seções destinadas à situação fática e ao seu contexto espaço-tempo podem ser estruturadas de diferentes formas. É recomendável que o texto contenha uma narrativa linear dos acontecimentos, permitindo ao leitor uma compreensão sequencial e gradativa do caso

\section{Conflito ou dilema do protagonista}

O conflito ou dilema do protagonista é o momento mais importante do texto. Deve conter os problemas e impasses, assim como as tentativas realizadas para resolvê-los. E, segundo Roesch (2011, p. 3), o texto deve encerrar "com algumas questões colocadas para desafiar a discussão pelos estudantes".

Ou seja, todo texto que narra um caso de ensino deve conter resumo, introdução, descrição da situação fática e de seu contexto espaço-tempo e o conflito ou dilema do protagonista.

O tamanho médio do texto de narração do caso, segundo Roesch (2011, p. 2), é de 10 páginas, normalmente dividido em seções (o que não é obrigatório). Ainda sobre o tamanho, é importante na elaboração de casos considerar o contexto em que será utilizado: tempo disponível, se será integralmente trabalhado em sala de aula (leitura, análise, discussão) ou se será trabalho em parte extraclasse (leitura e análise) e em parte em classe (discussão). Nesse sentido, o caso poderá ter de ser narrado em um texto curto (de duas a quatro páginas) ou poderá ser narrado em um texto mais longo (não devendo, entretanto, ultrapassar o tamanho de um artigo médio, para que possa ser lido em um período de tempo razoavelmente curto).

Especificamente quanto à narração, Roesch (2011, p. 3-6; 2007, p. 218-228) faz um conjunto de observações que seguem abaixo, aqui também adaptadas para a realidade de casos jurídicos:

\section{Descrição cronológica}

É recomendável uma descrição sequencial, que permita melhor entendimento do desenvolvimento dos acontecimentos que originaram os atuais problemas. As informações 12621200 vol.09, nº. 03, Rio de Janeiro, 2016. pp. 
devem ser precisas em termos em datas e locais; isso faz muita diferença em casos jurídicos. Sempre que possivel a narração deve ser linear, mas é possível segmenta-la através de flashbacks. É necessário considerar também o momento de corte do caso, o momento em que se encerra a narração. Considerando a elaboração de casos jurídicos, o momento fático que envolve o elemento central para o qual se busca a solução é uma boa alternativa para o momento de corte; continuar a narração a partir desse ponto pode comprometer a objetividade do texto, incluindo elementos posteriores que provavelmente não terão relevância para a solução a ser encaminhada. Entretanto, pode haver casos que possuam desdobramentos que também possuam relevância; casos sequenciais, nos quais há mais de um momento de corte.

\section{Apresentação de fatos}

A situação deve ser detidamente descrita. Descrições vagas não permitem o adequado enquadramento em termos jurídicos. Quando a situação descrita permitir, o uso de esquemas, diagramas, gráficos, quadros e tabelas é recomendável, pois pode auxiliar o leitor na sua compreensão, além de auxiliar na redução do tamanho do texto.

\section{Apresentação de personagens}

Para que o caso tome contornos realistas, mesmo quando for apenas uma descrição fictícia, é recomendável dar nomes às pessoas e instituições, bem como ao local e à época em que os fatos se situam. Quanto aos personagens, devem ter identificados sua idade e atividade, bem como outras informações que interessem para a melhor compreensão da situação e a adequada análise jurídica.

O escritor tem a opção de utilizar artifícios para melhor representar o pensamento e ações do protagonista e de outros personagens da história, por meio de suas falas, incidentes, diálogos, ou conversas ao telefone. Estes trazem o leitor para dentro da história. A leitura de crônicas, biografias e contos é recomendável para familiarizar o escritor com tais técnicas narrativas. (Roesch, 2011, p. 5).

\section{Ponto de vista da narração}

Pressupondo que se pretenda levar o leitor a identificar-se com o protagonista da situação, o recomendável é que o texto seja narrado do seu ponto de vista. Isso leva o leitor a se colocar no lugar do protagonista e lhe permite perceber e entender melhor a situação. Podem 
também ser apresentados pontos de vista de outros personagens, de forma a tornar mais rica e controversa a situação relatada. No campo do Direito, os pontos de vista do protagonista e dos demais personagens servem para indicar possibilidades jurídicas a serem analisadas.

\section{Narrador independente}

É recomendável que o leitor receba todas as informações necessárias e que lhe permitam analisar a situação - contexto, fatos, protagonista, etc. - e chegar, de forma independente, às suas próprias conclusões. A posição do escritor não deve, portanto, aparecer no texto, mesmo que de forma indireta. Em outras palavras, o texto não deve conter posicionamentos do seu autor que direcionem propositalmente o leitor em uma determinada direção. Esse tipo de situação pode ocorrer, mesmo não intencionalmente, através de elementos como a utilização de adjetivos elogiosos ou desqualificadores. Também é necessário cuidado com os títulos e subtítulos de seções, que devem ser redigidos com os termos mais neutros possíveis.

Assim, recomenda-se que no texto, somente os personagens venham a manifestar sua opinião e seu julgamento. Pela mesma razão, não cabe ao autor analisar os fatos à luz de teorias esta é tarefa para ser realizada pelos estudantes durante a discussão do caso em sala de aula. Tampouco, o autor deve citar a literatura (exceto se estiver se referindo a fontes estatísticas). (Roesch, 2011, p. 5).

\section{Sumários e cenas}

Denomina-se sumários os resumos de acontecimentos e cenas os acontecimentos que merecem destaques e são descritos de forma mais minuciosa. Longos períodos históricos são muitas vezes compactados em um único parágrafo; há, entretanto, momentos que precisam ser destacados, muitas vezes recorrendo a um diálogo entre personagens ou a uma fala (ou pensamento) do protagonista. Intercalar sumários e cenas introduz uma variação no texto que pode gerar maior interesse; mas é necessário ter cuidado, pois as cenas representam também uma quebra na narração, o que pode ter o efeito contrário.

A cena é uma quebra na narração. Seu uso faz sentido apenas quando representa um momento crucial da história. [...].

Para a construção de cenas, o pesquisador pode reproduzir parcialmente certos eventos captados por meio de entrevistas e observações, durante sua pesquisa de campo. Além disso, algumas cenas podem ser imaginadas pelo escritor. Entretanto, a inserção de elementos 12621200 vol.09, nº. 03, Rio de Janeiro, 2016. pp. 
ficcionais é permitida num caso, desde que estes sejam verossímeis e não distorçam os fatos. (Roesch, 2011, p. 6).

\section{Revisão do texto}

O texto precisa despertar o interesse do leitor. Frases e parágrafos curtos; ideias e descrições claras; transições textuais adequadas; correção gramatical; utilização de vocabulário adequado; informações pertinentes - ou seja, de um lado, todas as informações necessárias devem estar presentes e, de outro lado, devem ser evitadas as inclusões de informações desnecessárias.

Por fim, se faz importante uma ressalva. A forma mais frequente pela qual os casos são apresentados aos alunos é a escrita, por meio de material impresso e, em algumas situações, com cópias de autos de processos, pareceres, julgados e outros. Contudo, nada impede, por exemplo, que o caso seja apresentado por meio de filmes, vídeos ou obras literárias - integrais ou apenas trechos. Tais obras podem ser reais ou de ficção; o importante é que consigam transmitir com clareza o caso ao aluno.

Além do texto do caso em si, destinado aos alunos, é necessário também redigir um outro texto, destinado aos professores: é ele denominado de notas de ensino. Trata-se de documento a ser preparado pelo autor do caso e disponibilizado ao professor que irá aplicá-lo, contendo uma série de informações importantes. Assim, a nota conterá: um resumo do caso; descrições e características dos principais atores do caso; enquadramento no tempo e no espaço do caso; os conteúdos que devem ser abordados no caso; a justificativa e a pertinência de sua utilização em determinadas disciplinas; os objetivos pedagógicos da aplicação do caso, com a descrição dos conteúdos, competências e habilidades; sugestões do método de aplicação e avaliação do caso; e referências bibliográficas pertinentes ao tema do caso.

Roesch (2007, p. 228-229) esclarece que as notas de ensino, regra geral, não são publicadas com o caso, visto destinarem-se apenas aos professores. Segundo essa autora, as notas de ensino contêm os seguintes elementos: "(i) o resumo do caso; (ii) as fontes dos dados; (iii) os objetivos educacionais; (iv) alternativas para a análise do caso; (v) questões para a discussão do caso em sala de aula(6); e (vi) a bibliografia recomendada para fundamentar a discussão".

A Associação Nacional de Pesquisa e Pós-Graduação em Administração (ANPAD) elaborou um documento denominado Orientação para elaboração de casos para ensino; esse 
documento oferece uma síntese muito bem articulada do que deve estar contido nas notas de ensino:

\section{Notas de ensino}

Todos os Casos para Ensino deverão ser acompanhados das respectivas notas de ensino, que devem conter sugestões de uso do caso em sala de aula e colaborar para a obtenção de resultados didáticos. Neste sentido, as notas de ensino abordam:

a) Objetivos educacionais e a exposição do arcabouço teórico necessário à exposição ou discussão do caso, cujo volume de conceitos variará conforme o caso de ensino e sua área e subárea de escopo;

b) Aspectos pedagógicos relativos à aplicação do caso para ensino em sala de aula, contendo sugestões de dinâmicas de discussão do caso; a relação entre a dinâmica sugerida e os objetivos do caso; comportamentos esperados por parte dos alunos a partir da discussão; sugestões de utilização dos recursos e equipamentos disponíveis em sala por parte do professor; etc.;

c) Indicação de, pelo menos, 04 questões para discussão. Tais questões servirão como um guia para os alunos melhor estruturarem o problema e devem ter uma conotação mais analítica do que descritiva. O objetivo das questões é auxiliar o professor na aplicação do caso de ensino em sala de aula;

d) Análise das possíveis alternativas de decisões/soluções da situação organizacional enfocada no texto do caso, de forma a apoiar o trabalho do professor que aplicará o caso e colaborar com a obtenção de resultados relevantes na utilização do caso;

e) Registro de referências bibliográficas pertinentes aos conceitos abordados na exposição teórica e/ou indicações bibliográficas, a título de recomendação de leituras pertinentes com a situação descrita no caso. (ANPAD, 2012, p. 3-4).

Nem sempre o autor do caso é quem o aplicará aos alunos; por esse motivo se faz necessária a elaboração das notas de ensino ou notas explicativas. Elas são especialmente importantes na elaboração de casos destinados a compor o acervo de casotecas, nas quais os casos ficam à disposição de um grupo de professores (ou mesmo da comunidade em geral, em especial quando as casotecas são virtuais). Por isso, é imprescindível que contenham todas as informações necessárias para que possam ser adequadamente utilizados por docentes que não 
participaram da sua elaboração. Mas mesmo em situações em que o caso seja destinado ao próprio uso, a elaboração das notas de ensino serve como um elemento de teste do caso pelo próprio elaborador.

\section{ETAPAS DE APLICAÇÃO DO MÉTODO DO CASO}

Não existe uma regra ou fórmula preestabelecida para a aplicação do Método do Caso. A sua realização acaba variando em decorrência da área em que se está atuando, bem como da disciplina e da fase em que o estudo será aplicado. No entanto, algumas etapas comuns são pedagogicamente recomendáveis, visando atingir os objetivos de ensino:

\section{Primeira etapa}

A primeira etapa consiste na escolha de um caso real, ou formulação de um caso fictício, ou ainda, a adaptação e complementação de um caso real. Nessa linha, valem as considerações que foram feitas neste artigo acerca da escolha do caso.

\section{Segunda etapa}

A segunda etapa consiste na explicação da atividade e dos objetivos de aprendizagem e na preparação dos alunos para o estudo. Nessa etapa é fundamental que o professor, além de introduzir a metodologia (que pode ser inédita para alguns discentes), as regras e os resultados que se espera alcançar, motive os alunos a participarem de forma ativa e crítica da atividade.

\section{Terceira etapa}

$\mathrm{Na}$ terceira etapa o caso será apresentado aos alunos. Recomenda-se que o caso seja disponibilizado por escrito e que seja explicado de forma detalhada e oral pelo professor em sala de aula. Nesse passo o docente também entregará aos estudantes eventuais materiais complementares ao estudo, conforme já indicado neste artigo.

\section{Quarta etapa}

A quarta etapa consiste no desenvolvimento do estudo, o qual poderá ocorrer de forma individual ou em grupos, sendo ocupado horário de sala de aula ou não. Caso a atividade seja realizada em grupos é interessante a designação de um coordenador - que primará para que o trabalho seja conduzido em conformidade com o planejado e que todos o integrantes do grupo 
participem de forma ativa nas discussões e pesquisas - e um relator - que garantirá que todas as discussões, ideias e soluções levantadas pelo grupo sejam devidamente anotadas e relatadas, bem como será responsável pela consolidação final do estudo a ser apresentado. Nessa fase o professor terá um papel de orientador e facilitador do estudo, fazendo com que os alunos encontrem os locais corretos para a busca do conhecimento necessário à resolução do caso.

\section{Quinta etapa}

A etapa final consiste no debate sobre as soluções propostas, o agrupamento dos conteúdos que foram aprendidos, bem como na demonstração das habilidades e competências desenvolvidas. É recomendável que tal fase ocorra em sala de aula e seja coordenada pelo professor, o qual conduzirá os debates sobre as soluções propostas e realizará a atividade de consolidação do conteúdo, habilidades e competências. Importante o docente estar atento na condução da discussão, oportunizando tempo suficiente para cada aluno ou grupo expor suas ideias e propostas de solução e, principalmente, impedindo que se perca ou mude o foco dos objetivos da atividade.

Nada impede que a apresentação final do estudo ocorra na forma de simulação como, por exemplo, um caso de julgamento de uma apelação cível num tribunal de justiça. Os grupos podem ser divididos conforme a composição de julgamento (apelante, apelado, desembargadores e procurador de justiça) e, além de entregarem manifestações por escrito ao professor (apelação, contrarrazões, votos e parecer) um representante de cada grupo encenará o respectivo papel numa sessão de julgamento simulada. Situação semelhante ocorre na seara dos Cursos de Administração, com a ferramenta dos jogos de empresas:

Nos cursos participativos o 'role play' eì utilizado regularmente, com diferentes objetivos didáticos, como esclarecer conceitos ou exercitar a interação entre protagonistas virtuais. Nas aulas participativas em que o caso eì o principal veículo do aprendizado, o 'role play' pode ser muito eficaz na simulação da situaçaPo-problema e do processo decisório; seu objetivo maior eì dramatizar a participação virtual do aluno em alguma situação real. Nos jogos de empresa os participantes assumem papéis e fazem decisões, as quais vêm a ser avaliadas, dentro da 'lógica' do jogo, de acordo com critérios de boa estratégia, eficiência e realismo; ocorre premiação, como símbolo do sucesso ou insucesso na vida real nas organizações. (COSTA, 2007, p. 27). 
Todavia, essa atividade não elide, por óbvio, a necessidade da síntese final e consolidação do conteúdo, realizada pelo professor ou por um aluno relator (quando terá de ser revisada pelo professor).

\section{CONCLUSÃO}

Com o intuído de proporcionar uma maior facilidade para o aluno na compreensão dos conteúdos e desenvolvimento de competências e habilidades, se faz necessária a utilização das mais variadas estratégias didáticas. Por isso, é imprescindivel o docente ter ciência das inúmeras estratégias didáticas existentes, sabendo usá-las de forma inteligente no contexto da disciplina e do projeto pedagógico do curso.

Entre esses instrumentos está o Método do Caso, que consiste em interessante estratégia didática de ensino-aprendizagem, sendo ferramenta presente nas abordagens teóricas cognitivista, humanista e sociocultural. O Método do Caso, por ser estratégica focada no aluno, exige que ele tenha participação ativa, demonstrando interesse e curiosidade para a compreensão do conteúdo. A fim de possibilitar esse comportamento do aluno, o professor deve exercer papel de facilitador do conhecimento, estimulador do aprendizado, e contextualizador dos problemas.

Necessário é destacar que o Método do Caso apresentado neste artigo não se confunde com o Estudo de Casos, como método de pesquisa, e também não se confunde com a Aprendizagem Baseada em Problemas (ABP), mais conhecida como Problem Based Learning (PBL).

A utilização do Método do Caso, de forma adequada, pode lograr êxito na tarefa de alcançar os objetivos do processo de ensino-aprendizagem: compreensão dos conteúdos e o desenvolvimento de competências, habilidades e comportamentos.

Parece claro que a compreensão das teorias, das classificações, dos institutos básicos, dos conceitos e das categorias pode ocorrer de maneira satisfatória por meio do Método do Caso. Da mesma forma, não se pode olvidar que esse método possibilita ao aluno - diante de um problema que lhe é apresentado - o desenvolvimento de competências para: interpretar a situação; identificar e delimitar o problema posto; e apresentar as possíveis soluções para o problema.

Igualmente, o Método do Caso permite o desenvolvimento de habilidades, num plano mais prático de execução, para que o aluno, entre outros, aplique e teste as soluções levantadas para a resolução do problema. Na mesma linha, o método possibilita o desenvolvimento e avaliação de comportamentos, identificando os perfis dos alunos. 
A escolha e formulação do caso é fundamental para o êxito da metodologia. Por isso, o caso deve aproximar o aluno do mundo real, conjugando de forma prática as teorias e conhecimentos já obtidos. Deve ser um caso curioso, contextualizado com a realidade do aluno, daquela instituição de ensino e com o cenário socioeconômico no qual ele está inserido, possibilitando discussão e reflexão, bem como que admita uma solução ideal e possíveis soluções alternativas.

Em determinados tipos de casos é importante a disponibilização de material de apoio ao aluno, por exemplo, a íntegra dos autos da ação judicial em que os caso está sendo debatido, documentos, contratos, pareceres, análises técnicas, notícias de jornais, julgados dos tribunais superiores sobre o tema e outros.

Entre as diversas classificações existentes sobre os tipos de casos foi adotada, sem desconsiderar a importância das demais, uma classificação decorrente de uma simplificação da classificação formulada por Antônio Carlos Gil (2004, p. 11) para os casos utilizados nos Cursos de Administração.

Portanto, dividiu-se os tipos de casos em: (a) casos demonstração - são os casos elaborados para serem utilizados em aulas expositivas tradicionais, para ilustrar o conteúdo ministrado; e (b) casos problema - são os casos elaborados para serem utilizados no âmbito do Método do Caso; ou seja, são problemas elaborados para utilização em uma metodologia ativa, centrada no aluno e não no professor.

Quanto aos casos problema é possível: (a) um caso que já contenha no texto a sua solução (ou possíveis soluções) e os resultados obtidos da sua aplicação, onde se espera do aluno uma análise da situação como um todo, a identificação dos pontos positivos e negativos da solução que foi implementada e, principalmente, a proposição de soluções alternativas; (b) um caso em que é apresentado ao aluno tão somente uma situação ocorrida, devendo ele identificar os potencias problemas que podem surgir, analisar e propor soluções para cada um dos problemas e prever os resultados possíveis de cada uma destas soluções; (c) um caso em que se apresenta a situação ocorrida e os problemas já identificados e, diante disso, o aluno deverá propor soluções viáveis de resolução do problema, experimentando-as e, por conseguinte, identificando os resultados possíveis de cada uma dessas soluções; (d) um caso em que é apresentada a situação, o problema e a solução, mas sem indicar os resultados ou consequências decorrentes da decisão tomada, para que o aluno analise a solução proposta, com suas vantagens e desvantagens e identifique os possíveis resultados que serão obtidos com ela. 
A elaboração dos casos de ensino envolve seis estágios, a saber: (a) identificação do problema; (b) definição dos objetivos; (c) pesquisa e coleta de informações; (d) análise da dificuldade do caso; (e) construção do caso; e (f) teste do caso. No tocante à estrutura do caso é possível dizer que o texto que o narra deve conter: (a) resumo; (b) introdução; (c) descrição da situação fática e de seu contexto espaço-tempo; e (d) o conflito ou dilema do protagonista.

Quanto à narração dos casos é importante que quem o esteja elaborando observe as seguintes questões: (a) a descrição cronológica deve ser sequencial e permitir o melhor entendimento do desenvolvimento dos acontecimentos que originaram os atuais problemas; (b) na apresentação dos fatos a situação deve ser detidamente descrita evitando-se descrições vagas que possam levar ao inadequado enquadramento em termos jurídicos; (c) na apresentação dos personagens, para que o caso tome contornos realistas, é recomendável dar nomes às pessoas e instituições, bem como ao local e à época em que os fatos se situam; (d) quanto ao ponto de vista da narração é interessante que o texto seja narrado do ponto de vista do protagonista, de modo a levar o leitor a se colocar no seu lugar e, assim, permitir uma melhor percepção e entendimento da situação; (e) o narrador deve ser independente, ou seja, a posição do escritor sobre a questão não deve aparecer no texto, mesmo que de forma indireta; (f) os sumários (resumos de acontecimentos) e as cenas (relato dos acontecimentos que merecem destaques) devem ser intercalados ao longo do texto; e (g) a revisão do texto é de suma importância, pois é necessário que o mesmo contenha frases e parágrafos curtos, ideias e descrições claras, transições textuais adequadas, correção gramatical, utilização de vocabulário adequado e informações pertinentes.

Inexiste uma regra rígida para a aplicação Método do Caso, até mesmo em decorrência do fato de que a sua realização varia conforme a área em que se está atuando. Ainda assim, o artigo concluiu pela pertinência de um roteiro baseado em cinco etapas: (a) escolha e formulação do problema; (b) introdução e explicação da metodologia aos alunos; (c) apresentação do caso de forma escrita e oral; (d) desenvolvimento individual ou em grupo do estudo; e (e) debate final com a consolidação dos conteúdos compreendidos e das habilidades e competências desenvolvidas.

Espera-se, assim, que cada vez mais o processo de ensino-aprendizagem na Educação Jurídica preocupe-se com as estratégias didáticas focadas no aluno e, nessa quadra, a utilização do Estudo de Casos é ferramenta primordial. Contudo, deve-se atentar para que a mesma seja utilizada de forma adequada, dentro dos padrões estabelecidos e levando em conta as especificidades de cada disciplina ou matéria e do contexto educacional e socioeconômico dos alunos, sob pena de não serem alcançados seus objetivos. 


\title{
THE CASE METHOD IN LEGAL EDUCATION
}

\begin{abstract}
The article's object of study is the case method. Its target is to analyze the application of this tool within the legal education. Hence, the main theoretical approaches of the teaching-learning process are analyzed, highlighting those that are centered on the student; also the roles of the student and the teacher are identified for each approach. Following this stage, after delimitating the case method as a strategy focused on the student, boundaries and differences between the case method and the cases study will be drawn in order to justify the use, in this text, of the expression case method. Subsequently, it will be verified if the case method endorses the goals of the teaching-learning process regarding the comprehension of content and skills development, competences and behaviors. Afterwards, the study will analyze the types of cases that can be used, the required care for its selection and formulation, and presents a set of elements to be considered when preparing the cases. Finally, it presents the steps to be followed by the teacher to its proper use as a teaching strategy.
\end{abstract}

Keywords: Case method. Cases study. Teaching cases. Legal education. Law education.

\section{REFERENNCIAS}

ANPAD - Associação Nacional de Pesquisa e Pós-Graduação em Administração. Orientação para elaboração de casos para ensino. 2012. Disponível em: <http://www.anpad.org.br/Normas_Casos_para_Ensino_2012.pdf>. Acesso em 4 maio 2014.

CARLINI, Angélica Luciá. Aprendizagem baseada e problemas aplicada ao ensino de Direito: projeto exploratório na área de relações de consumo. São Paulo: PUC-SP, 2006. [Tese de Doutorado em Educação]. Disponível em: <http://www.sapientia.pucsp.br/tde_busca/arquivo.php?codArquivo=4118>. Acesso em 10 abr. 2014.

GHIRARDI, José Garcez; VANZELLA, Rafael Domingos Faiardo (org.). Ensino Jurídico participativo: construção de programas, experiências didáticas. São Paulo: Saraiva, Direito GV; 2008.

GIL, Antônio Carlos. Elaboração de casos para o ensino da Administração. Contextus: Revista Contemporânea de Economia e Gestão, Fortaleza, v. 2, n. 2, p.06-17, dez. 2004. Disponível em: <www.spell.org.br/documentos/download/21236>. Acesso em 22 abr. 2015.AM, Andrew. Como escrever e usar estudos de caso para ensino e aprendizagem no setor puìblico. Brasiìlia: ENAP, 2010. Disponível em: <http://www.enap.gov.br/images/livro_andrew_graham.pdf>. Acesso em 22 abr. 2015. 
GUIRALDELLI JÚNIOR, Paulo. A teoria educacional no ocidente: entre modernidade e pósmodernidade. São Paulo em Perspectiva, v. 14, n. 2, abr./jun. 2000, p. 32-36. Disponível em: 〈http://www.scielo.br/pdf/spp/v14n2/9785.pdf>. Acesso em 22 abr. 2015.

MENEZES, Maria Arlinda de Assis. Do método do caso ao case: a trajetória de uma ferramenta pedagógica. Educação e Pesquisa, São Paulo, v. 35, n. 1, p. 129-143. Jan./abr. 2009. Disponível em <http://www.scielo.br/pdf/ep/v35n1/a09v35n1.pdf>. Acesso em 22 abr. 2015.

RAMOS, Luciana de Oliveira; SCHORSCHER, Vivian Cristina. Método do Caso. In: GHIRADI, José Garcez. (org.). Métodos de ensino em Direito: conceitos para um debate. São Paulo: Saraiva, 2009. p. 49-60.

RODRIGUES, Horácio Wanderlei. Popper e o processo de ensino-aprendizagem pela resolução de problemas. Revista Direito GV, São Paulo, FGV, v. 6, n.1, jan.-jun. 2010, p. 39-57. Disponível em: <http://dx.doi.org/10.1590/S1808-24322010000100003>. Acesso em 22 abr. 2015.

Avaliação da aprendizagem nos Cursos de Direito: novas e velhas possibilidades. In: RODRIGUES, Horácio Wanderlei; ARRUDA JÚNIOR, Edmundo Lima de (org.). Educação Jurídica: temas contemporâneos. 3a ed. Florianópolis: Fundação Boiteux, 2014a. p. 255-278. Disponível em: 〈http://funjab.ufsc.br/wp/?page_id=1819>. Acesso em 22 abr. 2015.

Estratégias didáticas na Educação Jurídica: alternativas para o processo de ensinoaprendizagem nos Cursos de Direito. In: LIMA, Gretha Leite Maia Correia; TEIXEIRA, Zaneir Gonçalves. Ensino Jurídico: os desafios da compreensão do Direito. Fortaleza: Faculdade Christus, 2012. p. 323-354.

RODRIGUES, Horácio Wanderlei; MAROCCO, Andréa de Almeida Leite. Formação profissional, Núcleo de Prática Jurídica e método EARP como alternativa para as práticas simuladas. In: RODRIGUES, Horácio Wanderlei; SANCHES, Samyra Haydêe Dal Farra Naspolini; VERONESE AGUIAR, Alexandre Kehrig. Direito, Educação, Ensino e Metodologia Jurídicos. Florianópolis: CONPEDI, 2014b. p. 352-381. Disponível em: http://www.publicadireito.com.br/artigos/?cod=02923027376e61c1

ROESCH, Sylvia Maria Azevedo. Notas sobre a construção de casos para ensino. Revista de Administração Contemporânea. [online]. 2007, vol.11, n.2, pp. 213-234 Disponível em: <http://www.scielo.br/pdf/rac/v11n2/a12v11n2.pdf>. Acesso em: 22 abr. 2015

Como narrar um caso para ensino. GV Casos - Rev. Bras. de Casos de Ensino em Administração, 2011. Disponível em: <http://bibliotecadigital.fgv.br/ojs/index.php/gvcasos/article/download/3710/2328>. Acesso em 4 maio 2015.

SANTOS, Roberto Vatan dos. Abordagens do processo de ensino-aprendizagem. Integração, a. XI, n. 40, p. 19-31, jan./maio 2005. Disponível em: 〈ftp://www.usjt.br/pub/revint/19_40.pdf〉. Acesso em 22 abr. 2015.

SEBASTIANY, Giana Diesel; BASTOS, Marília Dornelles. Curso de Medicina da UNISC: a Aprendizagem Baseada em Problemas (ABP). Santa Cruz do Sul: EDUNISC, 2011.

TAGLIAVINI, João Virgílio. Aprender e ensinar Direito: para além do Direito que se ensina errado. São Carlos: Edição do Autor, 2013. 


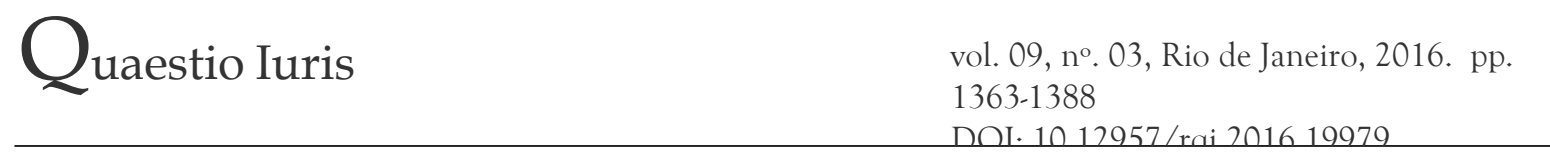

SILVA, Everton Rodrigues da; MARINHO, Yan. Caso de ensino: o que é e como ele pode auxiliar o ensino da Administração no Brasil. IX SEGeT, 2012. Disponível em: <http://www.aedb.br/seget/arquivos/artigos12/21316352.pdf >. Acesso em 4 maio 2015.

ZITSCHER, Harriet Christiane. Metodologia do Ensino Jurídico com casos - teoria \& prática. Belo Horizonte: Del Rey, 1999.

Trabalho enviado em 04 de dezembro de 2015.

Aceito em 23 de março de 2016. 